\title{
Remdesivir for COVID-19 pneumonia: still undecided, but it might all be about adequate timing
}

\author{
Vladimir Trkulja ${ }^{1}$ (D) \\ Received: 27 October 2020 / Accepted: 29 December 2020 / Published online: 6 January 2021 \\ (C) The Author(s), under exclusive licence to Springer-Verlag GmbH, DE part of Springer Nature 2021
}

To the Editor,

Two opposing claims were recently made about remdesivir in patients with COVID-19 pneumonia: the ACTT-1 trial claimed shortened time to recovery (vs. placebo) and (shyly) suggested reduced mortality [1], while the preliminary Solidarity trial report claimed no relevant benefit (vs. no treatment) in respect to any outcome [2]. Claims about a medically relevant benefit from remdesivir are indeed encompassed with a considerable uncertainty: (a) modestly shorter average time to recovery is hardly a major benefit (particularly considering the high drug acquisition costs); (b) reporting on mortality in patients with considerably different disease severity [1] is not particularly informative for practice; (c) only the patients requiring low-flow oxygen at randomization seem to have benefited [those requiring (i) high-flow oxygen or noninvasive ventilation (NIV), (ii) mechanical ventilation (MV)/ ECMO or no oxygen (a small subset) experienced no apparent benefit], but the subsets and analyses were defined post hoc [1]. Caveats related to decision-making based on estimates arising from such an approach have been well elaborated [3, 4]; (d) other (manufacturer-sponsored) trials [5, 6] failed to document a discernible treatment effect with an unclear relationship between a 5-day and a 10-day regimen [7]; (e) the Solidarity trial [2] indicated no relevant benefit regardless of the disease severity. However, in the report [2] patients requiring low-flow and those requiring high-flow oxygen were "mixed" together (other subsets were "no oxygen" and "ventilated" [NIV/MV]). It is sometimes overlooked that a lack of compelling evidence of a treatment effect is not necessarily evidence of its absence, i.e., that both claims (effect/no effect) could be burdened with uncertainty $[8,9]$. Figure 1a uses

Vladimir Trkulja

vladimir.trkulja@mef.hr

1 Department of Pharmacology, Zagreb University School of Medicine, Šalata 11, 10000 Zagreb, Croatia published data pertaining to mortality within 28-30 days since randomization, as available across different post hoc subsets (with inherent limitations) $[1,2,5,7]$ to illustrate both uncertainties. While the benefit in patients with severely compromised respiration (NIV/MV/ECMO, high-flow oxygen; or "ventilated") may be reasonably excluded, the uncertainty(ies) pertain to (a) the "no oxygen" subset, relatively large but with a low number of events and imprecise estimates not supporting existence of a practically relevant effect; (b) the "low-flow" oxygen subset which is, as currently presented, small, with imprecise estimates burdened with heterogeneity $\left(\tau^{2}, I^{2}\right)$ that cannot be distinguished from the estimates in the "no-effect" subsets; (c) the largest subset combining "lowflow" and "high-flow" oxygen patients, not confirming a benefit, but also not excluding it, with an estimate suggestive of a possibility that by mixing-in "high-flow" patients, the effect in "low-flow" patients was shifted towards unity. Figure $1 \mathrm{~b}$ illustrates these uncertainties accounting for correlation between subsets from the same trial. Figure $1 \mathrm{c}$ attempts to use all published randomized data pertaining to a mixed subset of "no oxygen" and "low-flow" oxygen patients to generate a network metaestimate that introduces further uncertainty about a claim of "no relevant effect" in these patients. Data in Fig. 1 could be reasonably considered as hypothesisgenerating particularly when combined with a medical rationale. It appears a priori implausible to expect a benefit from an antiviral treatment commenced in patients in whom the sequence of pulmonary events triggered by the virus most likely does not depend on its presence in the lower airways any more, or to expect it in patients in whom the baseline risk is generally low (e.g., patients who, after several days of pneumonia, are still well oxygenated). In this respect, it seems plausible to consider patients at the earlier stage of disease progression as the (only) potentially susceptible target population. This justifies a need for trials targeting specific disease severity populations in order to resolve the uncertainties. In the meantime, better use should be made of the considerable 


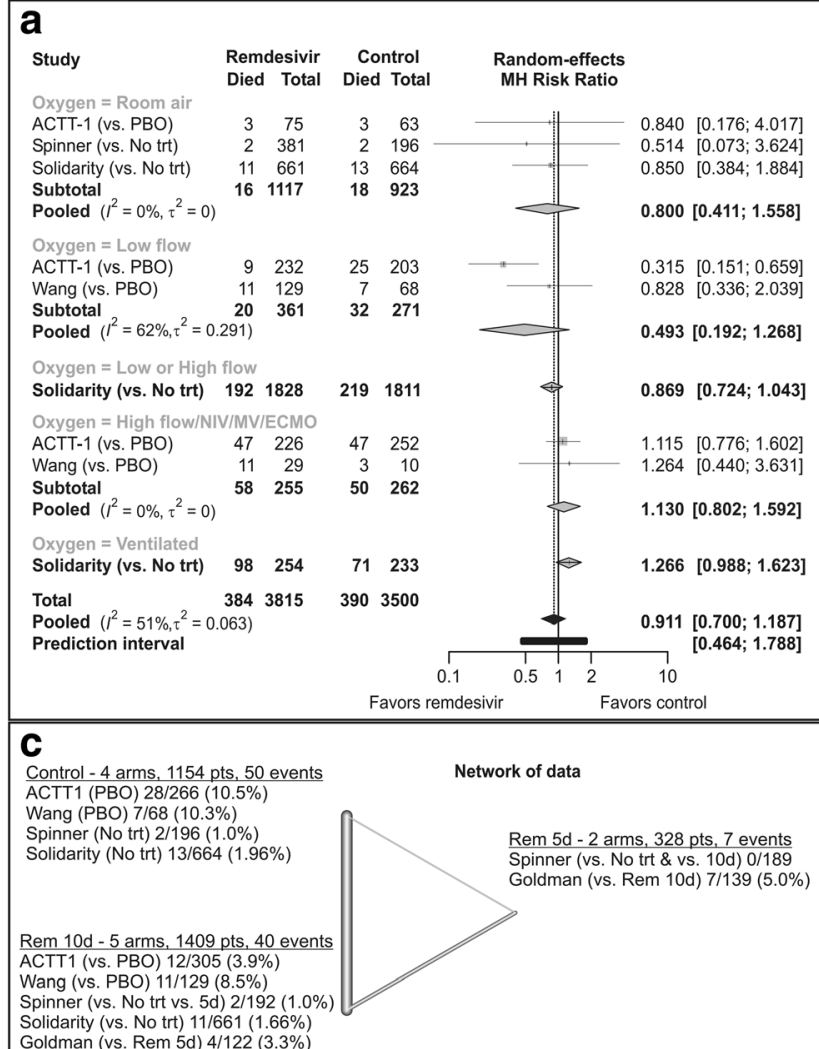

Solidarity (vs. No trt) $11 / 661(1.66 \%)$

Fig. 1 a Standard random-effects (Mantel-Haenszel risk ratio) metaanalysis of remdesivir vs. control (placebo, PBO, or no treatment, no trt) for the outcome "Death within 28-30 days since randomization" across subgroups of patients with a different level of respiratory failure (breath room air, need low-flow oxygen, high-flow oxygen, noninvasive ventilation [NIV], mechanical ventilation [MV], or extracorporeal oxygenation [ECMO]). Data are extracted as reported in the respective trials: data from ACTT-1 [1] were grouped as "room air", "low-flow oxygen" and as "high-flow, NIV/MV/ECMO" since remdesivir-placebo outcomes were practically identical in these subsets; in the trial by Spinner [6] $83 \%$ of all patients did not require oxygen, $1 \%$ were on high-flow oxygen or NIV, and 15-16\% were on low-flow oxygen, but their separate outcomes could not be identified. In Fig. 4 in the preliminary Solidarity report [2], they are all considered jointly. Here, those on high-flow oxygen or NIV were not considered. A total of 9 patients died by day 28: 3 on remdesivir 10-day treatment, 2 on remdesivir 5 -day treatment and 4 with no treatment [6] here, 2, 2, and 2 (by treatment arm) deaths are taken as if

amount of the exiting individual patient data to inform (interim) decisions on whether at all, and when, to use remdesivir.

\section{References}

1. Beigel JH, Tomashek KM, Dodd LE, Mehta AK, Zingman BS, Kalil AC, Hohmann E, Chu HY, Luetkemeyer A, Kline S, Lopez de Castilla D, Finberg RW, Dierberg K, Tapson V, Hsieh L, Patterson TF, Paredes R, Sweeney DA, Short WR, Touloumi G, Lye DC, Ohmagari N, Oh MD, Ruiz-Palacios GM, Benfield T, Fätkenheuer G, Kortepeter MG, Atmar RL, Creech CB, Lundgren J, Babiker AG, Pett S, Neaton JD, Burgess TH, Bonnett T, Green M, Makowski M, Osinusi A, b Random-effects pooled effect (odds ratio) of remdesivir on mortality within 28-30 days since randomization: results of multivariate models

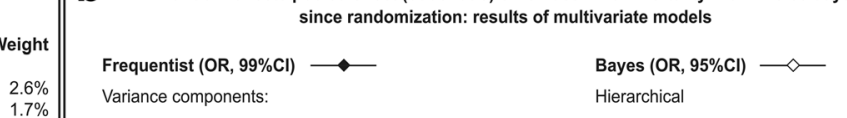

Outer factor= Trial (4 levels)

Prior for $\log (\mathrm{OR})=$ normal $(0,10 \mathrm{e} 4)$ Prior for $\tau^{2}=$ Half Cauchy $(0,0.5)$ $\begin{array}{ll}\text { Treatment * Oxygen demand } & \text { Random Oxygen, random Study }\end{array}$ $\begin{array}{ll}\text { Treatment * Oxygen demand } & \text { Random Oxygen, random } \\ \text { Residual heterogeneity: } \mathrm{QE}(\mathrm{df}=8)=16.58, \mathrm{P}=0.0348 & 4000 \text { iterations, thining }=2\end{array}$

\begin{tabular}{r||r|}
$8.9 \%$ & Residual heterogeneity: $\mathrm{QE}(\mathrm{df}=8)=16.58, \mathrm{P}=0.0348 \quad 4000 \mathrm{it}$ \\
$6.6 \%$ & $\mathrm{OR}(99 \% \mathrm{Cl} .95 \% \mathrm{Crl}$
\end{tabular}

$15.5 \%$ Oxygen: Room air

Oxygen: Low flow

Oxygen: Low or High flow

Oxygen: High flow/NIVIMVIECMO

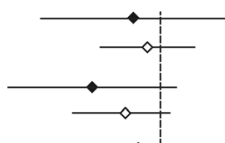

$0.67(0.17-2.68)$ $0.82(0.41-1.63)$

$0.37(0.11-1.27)$ $0.60(0.28-1.16)$

$0.72(0.32-1.64)$ $0.81(0.44-1.35)$ Oxygen: Ventilated

$1.18(0.56-2.46)$ $1.13(0.64-2.20)$ $1.22(0.46-3.24)$ $1.20(0.62-2.20)$

$0.05 \quad 0.1$

Favors remdesivir

Favors control

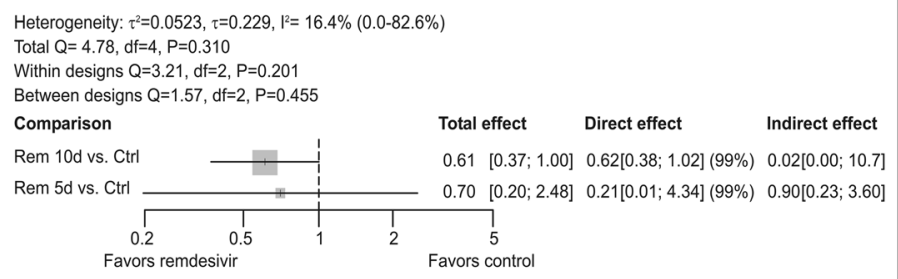

they had occurred in those patients on high-flow oxygen or NIV at baseline; data from Wang [5] could also not be clearly identified in respect to disease severity at baseline - here they are considered in the same way as in Fig. 4 in the Solidarity trial report [2]. Package meta in R was used [10]. b Summary of multivariate meta-analysis to account for correlation of effect estimates across subgroups from the same trial. Data are as in A. The frequentist method [11] is implemented in R, package metafor [12]. Estimates are provided with $99 \%$ CIs to account for multiplicity. The Bayesian analysis was performed by fitting a hierarchical model with an uninformative normal prior for $\log (\mathrm{OR})$. Implementation of Bayesian hierarchical models to meta-analysis is elaborated in [13] and was implemented in package brms in R [14]. $\mathbf{c}$ Left is the list of treatment arms in patients requiring no oxygen or low-flow oxygen identified across the remdesivir trials that form a network. Right is the result of random-effects network metaanalysis (the graph-theoretical method [15]) fitted in package netmeta in $\mathrm{R}$

Nayak S, Lane HC, ACTT-1 Study Group Members (2020) Remdesivir for the treatment of COVID-19 - final report. N Engl J Med 383:1813-1826. https://doi.org/10.1056/ NEJMoa2007764

2. Pan H, Peto R, Abdool Karim Q, Alejandria M, Henao-Restrepo AM, Hernandez Garcia $C$ et al (2020) Repurposed antiviral drugs for COVID-19 - interim WHO SOLIDARITY trial results. medRxiv. https://doi.org/10.1101/2020.10.15.20209817

3. Freemantle N (2001) Intepreting the results of secondary end points and subgroup analyses in clinical trials: should we lock the crazy aunt in the attic? BMJ 322:989-991

4. Peto R (2011) Current misconceptions: that subgroup-specific trial mortality results often provide a good basis for individualizing patient care. Br J Cancer 104:1057-1058

5. Wang Y, Zhang D, Du G, Du R, Zhao J, Jin Y et al (2020) Remdesivir in adults with severe COVID-19: a randomized, 
double-blind, placebo-controlled, multicenter trial. Lancet 395: $1569-1578$

6. Spinner CD, Gottlieb RL, Criner GJ, Arribas Lopez JR, Cattelan AM, Soriano Viladomiu A et al (2020) Effect of remdesivir vs standard care on clinical status at 11 days in patients with moderate COVID-19. A randomized clinical trial. JAMA 324:1048-1057

7. Goldman J, Lye DCB, Hui DS, Marks KM, Bruno R, Montejano R, Spinner CD, Galli M, Ahn MY, Nahass RG, Chen YS, SenGupta D, Hyland RH, Osinusi AO, Cao H, Blair C, Wei X, Gaggar A, Brainard DM, Towner WJ, Muñoz J, Mullane KM, Marty FM, Tashima KT, Diaz G, Subramanian A, GS-US-540-5773 Investigators (2020) Remdesivir for 5 or 10 days in patients with severe COVID-19. N Engl J Med 383:1827-1837. https://doi.org/ 10.1056/NEJMoa2015301

8. Altman DG, Bland MJ (1995) Absence of evidence is not evidence of absence. BMJ 311:485

9. Greenland S, Senn SJ, Rothman KJ, Carlin JB, Poole C, Goodman SN, Altman DG (2016) Statistical tests, P values, confidence intervals, and power: a guide to misinterpretations. Eur J Epidemiol 31: $337-350$
10. Schwarzer G, Carpenter JR, Rucker G (2015) Meta-analysis with R. Springer, Cham

11. van Houwelingen HC, Arends LR, Stijnen T (2002) Advanced methods in meta-analysis: multivariate approach and meta-regression. Stat Med 21:589-624

12. Viechtbauer W (2010) Conducting meta-analysis in R with the metafor package. J Stat Softw 36:1-48

13. Gelman A, Carlin JB, Stern HS, Dunson DB, Vehtari A, Rubin DB (2013) Hierarchical models. In: Bayesian data analysis, 3rd edn. CRC Press, pp 101-137

14. Burkner PC (2018) Advanced Bayesian multilevel modeling with $R$ package brms. R Journal 10:395-411

15. Rucker G (2012) Network meta-analysis, electrical networks and graph theory. Res Synth Methods 3:112-124

Publisher's note Springer Nature remains neutral with regard to jurisdictional claims in published maps and institutional affiliations. 